\title{
EFEK PENGGUNAAN BIOKAR DAN ASAP CAIR PADA LAHAN KELAPA SAWIT TERHADAP PRODUKSI DAN KUALITAS TANDAN BUAH SAWIT DAN ANALISIS NILAI TAMBAHNYA
}

\author{
Use of Biochar and Liquid Smoke in Palm Oil for Increase Quality of Palm Fruit and \\ Analysis of Economic Value-Added
}

\author{
Amos Lukas'), Suharto Ngudiwaluyo"1), Heru Mulyono2), Imran Rosyadi3), \\ Ishenny Mohd Noor $^{4)}$ dan P. Natsir La Teng ${ }^{5)}$ \\ 1) Pusat Sistem Audit Teknologi - BPPT \\ 2) Pusat Pengkajian Kawasan Spesifik dan Sistem Inovas i- BPPT \\ 3) Pusat Teknologi Agroindustri - BPPT \\ ${ }^{4}$ Inkubator Kampus Hijau - Pusat Penelitian dan Pelatihan Teknologi Internasional \\ Dr. Ishenny (P3TDI) Kota Langsa \\ 5) Balai Besar Industri Hasil Perkebunan \\ e-mail: natsir_lateng@yahoo.com
}

\begin{abstract}
Study the effect of biocar and liquid smoke from solid waste of palm oil mill to enhance products palm, quality of fresh palm fruit bunches (FFB), and economic value-added. The study was conducted in 2017 at Langsa-Aceh. The method used is the analytical method of comparing FFB products and FFB quality, between land treated with biocar 2 ton/ha and spraying liquids moke formulation : water $=1: 100$. Data collection through on-site observation, interviews from various parties, laboratory tests for the yield of CPO and the content of FFA. The results showed that the products of FFB increased from $19 \%$ to $28 \%$. The weight of FFB shows an increased of $17.5 \mathrm{~kg}$. to $25 \mathrm{~kg} / F F B$. Increased products of fresh fruit sign per Ha for a year of $223 \%$ and the quality of palm bunches that gave fresh fruit yields with 90-95\% better maturity uniformity, compared with not treatment which only reached $60-70 \%$. A higher yield of CPO $26-27 \%$ compared with no treatment of $19-21 \%$, FFA content $2-5 \%$ lower than with no treatment of 2-15\%. Application of biocar technology and liquid smoke can reduce the loss of economic value of Rp. $20.8484 \mathrm{~T}$. annually over 4.7 million Ha of palm oil in Indonesia
\end{abstract}

Keywords: FFA, biochar, liquid smoke, economic value-added

\begin{abstract}
Abstrak: Penelitian ini bertujuan melihat efek penggunaan biokar dan asap cair pada lahan kelapa sawit terhadap produksi dan kualitas Tandan Buah Sawit Segar (TBSS), dan nilai tambah ekonominya. Penelitian dilakukan pada tahun 2017 di Langsa-Aceh. Menggunakan metode analisis membandingkan produksi dan kualitas TBSS antara lahan yang diperlakukan dengan pemberian biokar 2 ton/ha, dan penyemprotan formulasi asap cair : air $=1: 100$ dengan lahan tanpa perlakuan. Pengumpulan data melalui pengamatan langsung di lokasi, wawancara dari barbagai pihak, uji laboratorium untuk rendemen CPO dan kandungan ALBnya. Hasil penelitian menunjukkan produksi TBSS meningkatkan dari $19 \%$ menjadi $28 \%$. Berat TBSS mengalami peningkatan dari 17,5 kg. menjadi $25 \mathrm{~kg} / \mathrm{TBSS}$. Peningkatan produksi TBSS/Ha. selama setahun sebesar $223 \%$ dan tingkat keseragaman kematangan buah $90-95 \%$ lebih baik, dibandingkan dengan tanpa perlakuan yang hanya sekitar $60-70 \%$. Rendemen CPO yang lebih tinggi $26-27 \%$ dibandingkan dengan tanpa perlakuan hanya $19-21 \%$, kandungan ALBnya $2-5 \%$ lebih rendah dibandingkan dengan tanpa perlakuan sebesar 2-15\%. Penerapan teknologi biokar dan asap cair dapat memberikan nilai tambah ekonomi sebesar Rp. 20,8484 T. pertahun atas 4,7 juta Ha lahan sawit di Indonesia
\end{abstract}

Kata kunci: TBSS, biokar, asap cair, nilai tambah ekonom.

\section{PENDAHULUAN}

Pertumbuhan sektor industri kelapa sawit yang cukup pesat, pada tahun 2017 mendapat tuduhan issue dari Parlemen
Uni Eropa yang bertujuan menghambat minyak sawit dari Indonesai menguasai pasar Eropa. Propaganda yang dilakukan seperti issu cendawan di musim hujan, adanya residu pestisida dan bahan kimia 
lainnya, deforestasi, praktek kerja anak dan memanfaatkan hutan ulayat (Kompas, 8 juni 2017). Usaha pemakzulan produksi minyak sawit Indonesia didukung oleh 640 anggota parlemen $(93,29 \%), 18$ anggota menolak $(2,63 \%)$ dan 28 anggota tidak memberikan suara $(4,08 \%)$. Dalam kondisi ini maka beberapa kemungkinan bisa terjadi seperti (1) Eropa saling berhubungan baik dan kompak, secara bilateral dan regional, saling berkongsi untuk sukseskan tujuan bersama dan (2) agar produsen sawit di Indonesia tunduk dan bisa disetir para pemilik modal dari eropa (Kompas, 8 Juni 2017)

Untuk menjawab tuduhan issue dari parlemen Eropa tersebut, dibutuhkan penerapan teknologi yang rama lingkungan, dapat meningkatkan produksi sawit organik, tanpa kandungan residu pestisida dan bahan kimia lainnya, menghambat pertumbuhan cendawan pada tanaman sawit di saat musim hujan, dan tanpa perluasan lahan sehingga tidak terjadi lagi pengurangan tanaman hutan ulayat dengan penerapan teknologi yang rama lingkungan.

Penelitian dalam rangka peningkatan produksi dan kualitas tanaman sawit agar mampu berdaya saing telah dilakukan di kampong Simpang Wi , kecamatan Langsa Lama-Kota Langsa.

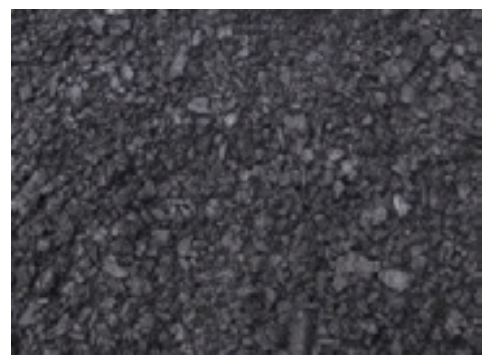

Gambar 1. Biochar TKSS, Produk Incinerator DR. Shenny Moh. Noor.

Produksi tandan sawit yang menurun akibat dari serangan hama, berkurangnya pemeliharaan tanaman sawit karena harga tandan sawit yang rendah, berkurangnya permintaan ekspor karena adanya proteksi dari Negara-Negara yang tergabung dalam Uni Eropa. Oleh sebab itu perlu segera di temukan solusinya dengan menggunakan teknologi dan sistem budidaya yang ramah lingkungan dengan memanfaatkan potensi yang ada di sekitarnya. Salah satu yang diperlakukan di dalam penelitian ini adalah dengan memanfaatkan biokar dan asap cair dari limbah tandan kosong kelapa sawit yang berlimpah.

Biokar yang dihasilkan dari limbah tandan kosong kelapa sawit (Gambar 1) melalui proses karbonisasi menggunakan alat karbonisator DR. Ishenny, menghasilkan biokar dengan partikel yang berukuran nano seperti pada Gambar 2 (Noor, 2015) (Amos et.all. 2017).

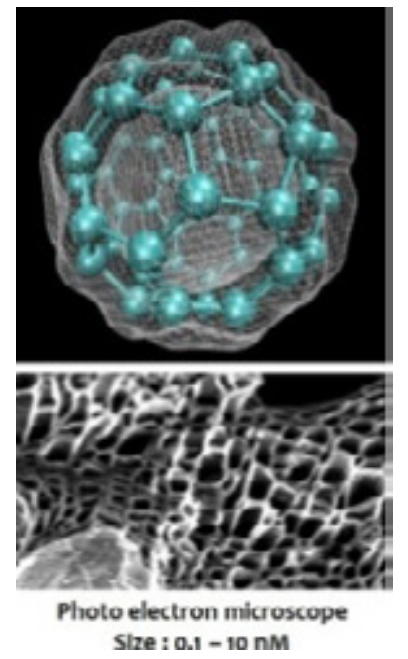

Gambar 2. Nano Biokarsize: $0.1-10$ nm

Menurut Plaza, et.all. 2016, dan Anderson, et.all., 2011, biokar dapat meningkatkan produksi tandan sawit, karena sifatnya, seperti; mengembalikan kesuburan tanah pada $\mathrm{pH}$ : 7.00-7.50, meningkatkan kandungan karbon tanah yang kaya oksigen, menyimpan air dalam tanah, menghasilkan nitrogen (Urea) melalui proses aktivitas mikroba tanah, meningkatkan porossitas/ kegemburan tanah sehingga akar dapat menembus tanah lebih dalam, meningkatkan produktivitas tanaman, memperpendek usia panen tanaman, meminimalisir penggunaan pupuk kimia, menghambat perkembangan hama tanaman, dan meningkatkan kualitas produk pertanian menjadi kualitas organik

Asap cair dapat bermanfaat untuk mencegah pertumbuhan cendawan pada 
tanaman sawit sehingga tanaman jadi sehat tanpa penggunaan pupuk dan festisida kimia. Hasil penelitian ini diharapkan dapat meningkatkan produksi dan kualitas tandan buah sawit segar dan produk turunan sawit dapat berdaya saing.

\section{METODOLOGI}

Penelitian ini menggunakan metode analisis, untuk memperoleh data perbandingan antara produksi dan kualitas tandan buah sawit segar pada beberapa pohon sawit yang tidak sehat, tidak berbuah lagi dan sudah hampir mati dengan perlakuan biokar dan asap cair dengan tanaman sawit yang masih segar tanpa perlakukan biokar dan asap cair. Perlakukan biokar dan asap cair pada tanaman sawit, adalah sebagai berikut ; a) memilih pohon yang tidak sehat dengan ciri-ciri daunnya kekuning-kuningan, ada serangan cendawan, tidak berbuah lagi dan juga sudah hampir mati, b) membuat lubang sedalam $30 \mathrm{~cm}$ dengan lebar $15 \mathrm{~cm}$ diantara pohon sawit seperti pada gambar 3 , c) menaburkan biokar secara merata pada lubang, yaitu seberat $5 \mathrm{~kg}$ setiap jarak antara pohon satu dengan pohon lainnya, sehingga memerlukan biokar sebanyak 2 ton/ha lahan, d) menimbun kembali biokar secara merata di antara pohon sawit, e) menyemprotkan formulasi asap cair:air $=1: 100$ secara merata pada batang dan daun tanaman yang terkena serangan cendawan, dan f) memberikan tanda pada tanaman yang diperlakukan untuk memudahkan pengamatan.

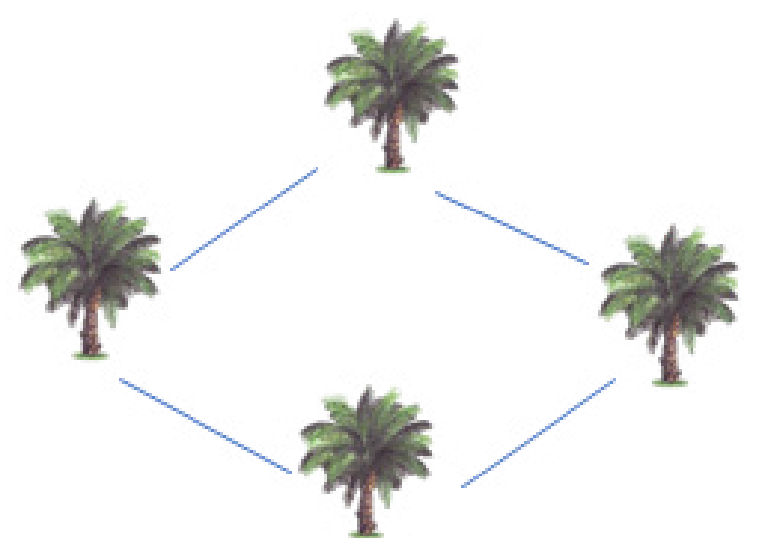

Gambar 3. Perlakuan Biokar
Pengamatan meliputi; pertumbuhan daun dan cendawan serta, tandan buah segar yang dihasilkan (berat rata-rata tandan buah segar, tingkat kematangan buah/ tandan, rendemen $\mathrm{CPO}$, dan kandungan ALB-nya)

Pengumpulan data dan informasi dilakukan melalui: 1) pengamatan langsung ke lokasi 2) wawancara dari berbagai pihak 3) meminta pendapat para pakar dan, 4) Uji Laboratorium terhadap rendemen CPO dan kandungan asam lemak bebasnya (ALB), dan 5) penelusuran referensi yang berkaitan dengan teknologi pengolahan sawit.

Efektifitas penggunaan biokar dan asap cair diukur dengan membandingkan tanaman sawit yang mengalami perlakuan biokar dan asap cair dengan yang tidak mengalami perlakuan biokar dan asap cair. Perbandingan jumlah produksi tandan buah segar sawit, kontinuitas pembuahan sepanjang tahun, produksi TBSS dan mutunya serta tingkat keseragaman kematangan buah dalam satu tandan.

Kualitas/mutu tandan buah segar yang dihasilkan dilihat dari kualitas tandan buah segar terkait dengan rendemen CPO dan kandungan asam lemak bebasnya (ALB) melalui Uji Laboratorium di Laboratorium Penelitian DR. Ishenny Moh. Noor, serta dampak terhadap produk dengan kualifikasi sawit organik.

Penelitian dilakukan di Kampong Simpang Wi, Kecamatan Langsa Lama, Kota Langsa, Provinsi Aceh.

\section{HASIL DAN PEMBAHASAN}

\section{Biokar}

Biokar yang di manfaatkan sebagai media tanam dapat meningkatkan karbon tanah dari $0,4-0,7 \%$ menjadi $2 \%$, meningkatkan: kualitas fisik dan kimia tanah, daya simpan air tanah, daya simpan pupuk untuk kebutuhan tanaman, kandungan oksigen dalam tanah, aktivitas perkembang-biakan mikroorganisme tanah dan meningkatkan nutrisi tanah (Anderson, et.all., 2011) 
Pengamatan lapangan menunjukkan bahwa setelah pemberian biokar dari karbonisasi tandan kosong kelapa sawit, yang bersifat nano, pada tanaman sawit yang tidak sehat dan sudah hampir mati, memperlihatkan bahwa terjadi perubahan yang signifikan dari warna daun yang kekuning-kuningan dan sudah hampir mati kembali menjadi tanaman yang sehat yang ditunjukkan dengan daun yang kembali berwana hijau tua, segar dan berkilat. Hal ini sebagai akibat ketersediaan air yang cukup dan reaksi foto sintetis meningkat. Biokar memiliki beberapa sifat yang menguntungkan karena dapat menyediakan suplay nutrisi yang cukup bagi pertumbuhan, perkembangan dan kesehatan tanaman sawit yang pada akhirnya tanaman sawit akan berbuah sepanjang tahun. Pemberian biokar dilakukan cukup sekali dalam jangka waktu 5 tahun (Plaza, et.all., 2016).

Menurut Plaza, et.all., 2016, dan Liu, et.all., 2012, aplikasi pemanfaatan biokar sebagai media tanam, memberikan manfaat seperti; mengembalikan kesuburan tanah pada $\mathrm{pH}$ : 7.00-7.50, meningkatkan kandungan karbon tanah yang kaya oksigen, menyimpan air dalam tanah, menghasilkan nitrogen (Urea) melalui proses aktivitas mikroba tanah, meningkatkan kegemburan tanah sehingga akar dapat menembus tanah lebih dalam, meningkatkan produktivitas tanaman, memperpendek usia panen tanaman, meminimalisir penggunaan pupuk kimia, menghambat perkembangan hama tanaman, meningkatkan kualitas produk pertanian menjadi kualitas dengan kualifikasi organik, dan meningkatkan pendapatan petani.

Biokar dengan ukuran nano yang dapat menyimpan air, udara serta tempat hidup mirokba yang menyehatkan tanah dapat berfungi meningkatkan kualitas fisik dan kimia tanah, daya simpan nutrisi meningkat, meningkatkan kandungan oksigen dalam tanah, aktivitas perkembangbiakan mikroorganisme tanah meningkat dan akhirnya meningkatkan nutrisi tanah yang sangat baik untuk peningkatan produksi dan kualitas tanaman sawit.
Hasil dari aplikasi pemanfaatan biokar untuk meningkatkan kuantitas dan kualitas tandan buah sawit segar, mekanisme kerjanya pada tahap awal mengembalikan kesuburan tanah tanaman sawit pada $\mathrm{pH}$ : 7.00-7.50, meningkat kandungan karbon tanah yang kaya oksigen, mampu menyimpan air yang diperlukan tanaman, menghasilkan nitrogen (Urea) melalui proses aktivitas mikroba tanah, meningkat porossitas/kegemburan tanah sehingga akar sawit mampu menembus tanah lebih dalam, meningkatkan hasil buah tandan sawit $100 \%$ (tabel 1), mampu menjadikan tanaman sawit berbuah terus menerus sepanjang tahun, tanpa ada jedah , meniadakan/ minimalisasi penggunaan pupuk kimia, meminimalisir serangan hama tanaman tanpa menggunakan pestisida kimia, meningkatkan kualitas produk pertanian menjadi kualitas organik, dan pada akhirnya meningkatkan pendapatan petani hingga Rp. 50-100 juta/tahun.

\section{Asap Cair}

Setelah penyemprotan formulasi asap cair: air (1 : 100) pada daun dan batang tanaman sawityang tidak sehat dan terserang hama cendawan dan jamur (Gonodermasp) yang menyerang akar tanaman, batang dan daun tanaman sawit kembali menjadi sehat dan segar, produksi TBS meningkat. Kualitas TBS yang dihasilkan tanpa menggunakan pupuk kimia dan pestisida kimia menjadikan produk TBS yang siap menuju produk yang berkualifikasi organik (sementara dalam proses sertifikasi).

Asap cair yang digunakan untuk meningkatkan kualitas dan kuantitas tandan buah sawit adalah asap cair yang berwarna coklat gelap, rasa asam kuat, aroma asap kuat (grade 3) (Budijanto, et.all., 2008), dengan pengenceran 100 kali, (1 liter asap cair di tambahkan dengan 100 liter air) dan di semprotkan merata pada bagian tanaman sawit yang terserang oleh cendawan yang di lakukan setiap 10 hari, sampai pohon sawit pulih dari serangan hama cendawan. 
Proses pirolisis yang terjadi di dalam karbonisasi limbah tandan kosong kelapa sawit menghasilkan senyawa kimia yang kompleks. Senyawa kimia yang kompleks tersebut mengandung berbagai komponen senyawa dan beberapa metode pemisahan telah banyak dilakukan untuk memisahkan komponen senyawa tersebut berdasarkan polaritas, tingkat keasaman, dan volatilitas (Putnam, et.all., 1999).

Asap cair salah satu hasil pirolisis tandan kosong kelapa sawit yang di karbonisasi dengan suhu sekitar $200{ }^{\circ} \mathrm{C}$ dengan bantuan BSF (Biocatalyst Fuels Technology), Gambar 4. Asap cair yang di hasilkan mempunyai banyak keuntungan dan lebih mudah diaplikasikan, proses lebih cepat, memberikan karakteristik yang khas pada produk akhir berupa aroma warna, dan rasa, serta penggunaannya tidak mencemari lingkungan.

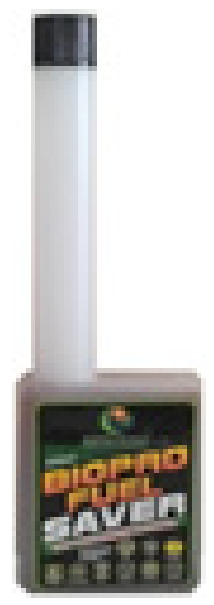

Gambar 4. BSF (Biocatalyst Fuels Technology)

Asap cair mengandung komponenkomponen seperti fenol, asam organik dan karbonil yang berfungsi sebagai antibakteri, antijamur dan koagulan. Senyawa-senyawa tersebut juga mempunyai peranan sebagai pemberi cita rasa yang khas (Jayanudin dan Endang Suhendi, 2012) (Girrard, 1992).

Kualitas asap cair ditentukan dari komposisi fenol, dan asam. Besarnya komponen tersebut dipengaruhi oleh kondisi operasi proses pirolisis yaitu suhu dan waktu pirolisis serta suhu distilasi. Asap cair mengandung berbagai komponen kimia seperti fenol, aldehid, keton, asam organik, asetat dan ester (Guillen, et.all., 1995; Guillen, dkk., 2000; Guillen, et.all., 2001). Berbagai komponen kimia tersebut dapat berperan sebagai antioksidan dan antimikroba serta memberikan efek warna dan cita rasa khas asap pada produk pangan (Karseno, et.all., 2002).

Pirolisis adalah dekompisisi bahan yang mengandung karbon dari tumbuhan, hewan dan bahan tambang yang dapat berlangsung pada suhu diatas $300^{\circ} \mathrm{C}$ dalam waktu 4-7 jam pada kondisi udara/oksigen terbatas menghasilkan produk padatan, cairan dan gas (Gani 2007; Demirbas, 2005 dan Di Blasi, 2008). Asap cair merupakan hasil dari dekomposisi selulosa, hemiselulosa dan lignin melalui proses pirolisis. Penghilangan air dari kayu pada suhu $120-150^{\circ} \mathrm{C}$, pirolisa hemiselulosa pada suhu $200-250^{\circ} \mathrm{C}$, pirolisa selulosa pada suhu $280-320^{\circ} \mathrm{C}$ dan pirolisa lignin pada suhu $400^{\circ} \mathrm{C}$.

Pirolisis pada suhu $400^{\circ} \mathrm{C}$ ini menghasilkan senyawa yang mempunyai kualitas asap cair yang tinggi dan pada suhu lebih tinggi lagi akan terjadi reaksi kondensasi pembentukan senyawa baru dan oksidasi produk kondensasi diikuti kenaikan linier senyawa tar dan hidrokarbon polisiklis aromatis (Luditama dan Candra, 2006).

Asap cair yang di hasilkan dari proses karbonisasi limbah tandan kosong kelapa sawit dengan bantuan BSF (Biocatalyst Fuels Technology) dikelompokkan dalam 3 (tiga) spesifikasi atau grade (Budijanto et al, 2008), yaitu : (Grade 1) warna bening, rasa sedikit asam, aroma netral, dan sangat baik untuk di aplikasikan pada pengawetan makanan dan ikan, (Grade 2) warna kecoklatan transparan, rasa asam sedang, aroma asap lemah, sangat baik digunakan untuk makanan dengan taste asap (daging asap, bakso, mie , tahu, ikan kering, telur asap, bumbu barbeque dan ikan bandeng asap dan (Grade 3) warna coklat gelap, rasa asam kuat, aroma asap kuat, sangat baik digunakan untuk penggumpalan karet pengganti asam semut, menghilangkan jamur dan bakteri di 
tambak ikan, menghilangkan bau busuk dan pembersih lantai di peternakan ayam.

\section{Tandan Buah Segar Kelapa Sawit}

Produk yang dihasilkan dari tandan buah sawit tersebut menjadi produk dengan kualifikasi organik dan kuantitas yang meningkatkan, seperti terlihat pada Tabel 1 , berikut.

Tabel 1. Hasil Pengamatan, Perlakuan pada Sawit Umur 8 Tahun, Masa Efektif Perubahan dalam Waktu 2 Bulan, dan Perubahan Setelah 1 Bulan

\begin{tabular}{|l|l|}
\hline \multicolumn{1}{|c|}{$\begin{array}{c}\text { Tidak Pakai Biokar } \\
\text { dan Asap Cair }\end{array}$} & \multicolumn{1}{c|}{$\begin{array}{c}\text { Menggunakan Biokar } \\
\text { dan Asap Cair }\end{array}$} \\
\hline $\begin{array}{l}\text { Tanaman kurang segar, kelihatan kekurangan } \\
\text { air, warna daun kuning kehijauan, reaksi } \\
\text { pohosintesis lambat }\end{array}$ & $\begin{array}{l}\text { Warnadaun hijau Tua dan berkilap, segar, } \\
\text { menunjukan ketersedian air yang cukup, reaksi } \\
\text { potosintesis meningkat }\end{array}$ \\
\hline Tandan buah 15 - 20 kg per tandan & Tandan buah 20 - 30 kg / tandan \\
\hline Buah ada waktu istiarahat/jeda & Berbuah sepanjang tahun tanpa ada masa jeda \\
\hline $\begin{array}{l}\text { Hasil tandan dalam setahun/ha adalah 5-10 } \\
\text { ton }\end{array}$ & Hasil tandan buah dalam setahun 20 - 40 ton \\
\hline $\begin{array}{l}\text { Tidak tahan terhadap serangan yang } \\
\text { menyerang akar (Gono derma) }\end{array}$ & $\begin{array}{l}\text { Tahan terhadap serangan hama yang menyerang } \\
\text { akar (Gono derma) }\end{array}$ \\
\hline Menggunakan pestisida dan pupuk kimia & Tanpa pestisida dan pupuk kimia \\
\hline Keseragaman kematangan buah 60-70\% & Keseragaman kematangan buah 90-95\% \\
\hline Rendemen CPO 19-21\% & Rendemen CPO 26-27\% \\
\hline Asam Lemak bebas 2-15\% & Asam lemak bebas 2-5\% \\
\hline
\end{tabular}

Berdasarkan pengamatan terhadap tandan segar yang dihasilkan diyakini tidak ada perubahan komposisi kimia didalamnya karena biokar hanya memperbaiki nutrisi dan mengkondisikan lahan yang sehat dan dapat di tumbuhi tanaman, namun dengan kuantitas berat tanda segar sawit di yakini, menaikan rendemen kandungan CPO dan menurunkan kandungan asam lemak bebasnya (ALB), oleh factor tingginya keseragaman kematangan buah dalam satu tandan. Terjadi peningkatan kuantitas tandan segar sawit dan di beli oleh pabrik dengan harga yang sama, berarti ada peningkatkan pendapatan kepada petani sawit, hal ini di yakini oleh pabrik bahwa tidak ada perubahan komposisi kandungannya, namun rendemen CPO dan asam lemaknya di yakini akan lebih baik.

Tanaman Kelapa sawit berakar serabut yang terdiri atas akar primer, skunder, tertier dan kuartier. Akar-akar primer pada umumnya tumbuh ke bawah, sedangkan akar skunder, tertier dan kuartier arah tumbuhnya mendatar dan bawah. Akar kuartier berfungsi menyerap unsur hara dan air dari dalam tanah. Akar-akar kelapa sawit banyak berkembang di lapisan tanah atas sampai kedalaman sekitar 1 (satu) meter dan semakin ke bawah semakin sedikit (Setyamidjaja, 2006).

Tandan buah tumbuh di ketiak daun, semakin tua umur kelapa sawit, pertumbuhan daunnya semakin sedikit, sehingga buah terbentuk semakin menurun. Hal ini disebabkan semakin tua umur tanaman, ukuran buah kelapa sawit akan semakin besar. Kadar minyak yang dihasilkannya pun akan semakin tinggi. Berat tandan buah kelapa sawit bervariasi, dari beberapa ons hingga $30 \mathrm{~kg}$ (Setyamidjaja, 2006).

$\mathrm{Di}$ daerah-daerah yang musim kemaraunya tegas dan panjang, pertumbuhan tanaman kelapa sawit dapat terhambat, yang pada gilirannya akan berdampak pada produksi buah. Suhu berpengaruh pada produksi melalui laju reaksi biokimia dan generative dalam tubuh 
tanaman. Sampai batas tertentu, suhu yang lebih tinggi menyebabkan meningkatnya produksi buah. Suhu $20^{\circ} \mathrm{C}$ disebut sebagai batas minimum bagi pertumbuhan generative dan suhu rata-rata tahunan sebesar $22-23^{\circ} \mathrm{C}$ diperlukan untuk berlangsungnya produksi buah (Mangoensoekarjo dan Semangun, 2005).

Penyakit busuk pangkal batang (BPB) pada tanaman kelapa sawit disebabkan oleh jamur Gonoderma boninense Pat., suatu jamur tanah hutan hujan tropis. Jamur $G$. Boninense bersifat saprofitik (dapat hidup pada sisa tanaman) dan akan berubah menjadi patogenik bila bertemu dengan akar tanaman kelapa sawit yang tumbuh di dekatnya. Penyakit BPB dapat menyerang tanaman mulai dari bibit hingga tanaman tua, tetapi gejala penyakit biasanya baru terlihat setelah bibit ditanam di kebun.

Busuk pangkal batang pada tanaman kelapa sawit dapat dikendalikan dengan menggunakan asap cair hasil karbonisasi tandan kosong kelapa sawit. Penyemprotan asap cair grade 3 hasil dari proses karbonisasi memberikan hasil yang positif setelah 2 bulan, tanaman sawit menjadi sehat dan akhirnya dapat meningkatkan produk dan kualitas tandan buah sawit.

\section{Hasil Uji Laboratorium}

Hasil uji laboratorium yang dilakukan di Laboratorium Penelitian DR. Ishenny Moh. Noor menunjukkan, rendemen CPO tandan buah segar dari tanaman yang diperlakukan dengan biokar dan penyemprotan formulasi asap cair mengalami peningkatan menjadi $26-27 \%$ sedangkan yang tidak mengalami perlakuan hanya sekitar19-21\%. Hal ini disebabkan karena tanaman sawit menjadi sehat yang ditandai dengan kenampakan daunnya yang hijau segar dan mengkilap. Kandungan ALBnya yang rendah, hanya 2-5 \% dibandingkan dengan ALB dari tandan sawit yang tidak mengalami perlakuan sebesar $2-15 \%$, hal ini sebagai akibat langsung dari tingkat keseragaman kematangan buah yang tinggi (90-95\%) dalam 1 (satu) tandan, sedangkan yang tidak mengalami perlakuan, kematangan buah hanya berkisar antara $60-70 \%$.

\section{Nilai Tambah Ekonomi}

Keuntungan lain yang dapat diperolah dari penggunaan biokar pada tanaman sawit adalah tumpang sari dengan sayuran kangkung dan sawi yang dengan melakukan penyemprotan asap cair grade 1 (satu) menghasilkan sayuran berkualifikasi organik. Kegiatan ini akan menghasilkan pendapatan sebesar 20 juta/ha/bulan. Peningkatan kuantitas tandan sawit dari $15-20 \mathrm{~kg}$ menjadi $20-40 \mathrm{~kg}$, dan rata-rata peningkatan produksi dari $17,5 \mathrm{~kg}$ menjadi $30 \mathrm{~kg}$. Peningkatan rata-rata produksi tandan sawit sebesar $71.43 \%$, dengan penambahan biaya kebutuhan biokar sebesar Rp. 7.500,-/ pohon untuk jangka waktu selama 5 tahun dan penyemprotan asap cair perpohon perbulan adalah sebesar Rp. 6.500,-

Akibat rendahnya produktivitas perkebunan sawit rakyat yang luasnya 4,7 juta hektar ini, ada potensi kehilangan yang setiap tahunnya bisa mencapai Rp 120 triliun. "Kita kehilangan setahun Rp. 120 triliun karena enggak mampu meningkatkan produktivitas perkebunan sawit. Diungkapkannya, rendahnya produktivitas kebun sawit rakyat ini karena dua sebab yang paling dominan, yakni usia tanaman yang sudah tua, serta bibit pohon sawit yang tidak berkualitas".(Dirjen Perkebunan, Detik, Selasa, 29 Agustus 2017)

Rata-rara dalam 1(satu) ha. Iahan tanaman sawit, terdapat 136 pohon, berarti dalam satu ha. tanaman sawit bisa terjadi peningkatan produksi dari $2.380 \mathrm{~kg} / \mathrm{ha}$ menjadi $3.400 \mathrm{~kg} / \mathrm{ha} / \mathrm{sekali}$ musim buah. Tanaman sawit tanpa perlakukan biochar dan asap cair ada masa jedah (istirahat berbuah) sementara pembuahan pada tanaman sawit yang menggunakan biokar dan asap cair tampak berbeda karena berbuah terus menerus sepanjang tahun tanpa jeda. Perhitungan rata-rata panen tandan segar sawit tanpa perlakukan adalah 7,5 ton/tahun dan dengan perlakuan biokar dan asap cair ada peningkatan rata- 
rata dalam setahunnya sebesar 25 ton/ha. Perkiraan peningkatannya adalah sebesar 233\% dengan demikian tidak perlu lagi meningkatkan produksi dengan memperluas lahan perkebunan sawit, melainkan dengan memanfaatkan teknologi biokar yang bahan bakunya adalah tanda kosong kelapa sawit yang melimpah, mampu meingkatkan produksi tanda segar.

Potensi keuntungan yang akan di peroleh untuk per ha. kebun sawit dalam setahun dengan menerapkan teknologi biokar dan asap cair adalah sebesar 17.500 x Rp 800,-(harga Tandan segar per-kg) adalah sebesar Rp. 14.000.000,-. Luasan kelapa sawit yang pada tahun 2017 mencapai 4.700.000 Ha, maka potensi kehilangan akibat belum dioptimalkan produksi tandan segar sawit adalah sebesar Rp. 65.800.000.000.000,- (Rp. 65,8 Triliun)

Biaya yang di butuhkan untuk penerapan teknologi peningkatan produk dan kualitas pertahun/ha-nya adalah sebesar Rp. 11.628.000,- (penerapan biokar dan asap cair), sehinga keuntungan yang akan di peroleh dengan harga jual tanda buah segar terendah yaitu Rp. 800/kg, per ha. adalah sebesar Rp.2.372.000,-. Bila di terapkan untuk luasan 4.700.000 Ha., perkiraan tambahan yang akan diperoleh adalah sebesar Rp. 11.148.400.000.000,- (Rp 11,148.4 T)

Selain terjadi peningkatan produksi tandan sawit segar juga meningkatkan kualitas, tandan sawit segar, menjadikan produk berkualifikasi organik karena tidak lagi menggunakan pupuk dan pestisida berbahan kimia. Untuk beberapa tahun setelah penerapannya dapat mengajukan sertifikasi produk organik tandan sawit yang dihasilkan. Produk ini akan menjawab issue ataupun tantangan dari negara Uni Eropa yang menghambat ekspor produk sawit Indonesia.

Produk organik menjadi tren sejak abad millinium dan tandan segar yang organik juga akan meningkat harganya pada suatu saat nanti dan mulai sekarang mendorong agar dilakukan perlakuan biochar dan asap cair
Selain keuntungan yang diperolah dari peningkatan kuantitas tandan segar sawit, masih ada peluang dari tanaman tumpang sari sayur kangkung dan sawi organik yaitu sebesar Rp.20.000.000/ha/tahun. Potensi kehilangan dengan jumlah 4.700 .000 Ha. tanaman sawit adalah sebesar Rp. 9.700.000.000.000 (Rp. 9,7 T), berarti ada peluang untuk mendapatkan penghasilan sebesar Rp. 20.848.400.000.000,- (Rp 20, $8484 \mathrm{~T}$ )

Hasil penelitian ini baru di lanjutkan ke tahapan yang lebih besar agar di dapatkan nilai yang signifikan sehingga di dalam penerapannya dalam skala besar bisa memberikan hasil yang signifikan dengan apa yang telah di lakukan dalam skala 1 ha.

\section{KESIMPULAN}

Penerapan teknologi biokar yang berukuran nano dan penyemprotan formulasi asap cair secara rutin setiap sepuluh hari pada tanaman sawit yang terserang cendawan merupakan teknologi ramah lingkungan, tidak menggunakan pupuk dan pestisida berbahan kimia dan telah terbukti dapat meningkatkan produksi dan kualitas tandan buah sawit segar tanpa perluasan lahan. Pemakaian biokar pada tanaman sawit, cukup sekali dalam jangka waktu 5 tahun (Plaza et al, 2016). Hal ini menjawab issue negatip dari Negara Uni Eropa tentang produk sawit Indonesia.

Potensi kehilangan nilai ekonomi dari pendapatan 4,7 juta ha. tanaman sawit yaitu sebesar Rp. 65,8 Triliun, dapat dicegah dengan penerapan teknologi biochar dan asap cair. Penerapan teknologi biokar dan asap cair dapat mengurangi kehilangan nilai ekonomi, dan memberikan tambahan nilai ekonomi sebesar Rp. 20,848.4 T. dari peningkatan produksi dan kualitas tandan sawit segar dan tumpang sari tanaman sayuran di celah-celah tanaman sawit

\section{SARAN}

Perlu segera didapatkan data analisa penggunaan biokar dan asap cair yang optimum untuk setiap pohon sawit dan 
sertifikasi organik produk tandan segar yang dihasilkan setelah melewati persyaratan panen dan tahapan panen untuk beberapa waktu lamanya.

\section{DAFTAR PUSTAKA}

1. Amos Lukas, Suharto Ngudiwaluyo, Ishenny Mohd. Noor dan P. Natsir La Teng, 2017 Aplikasi Teknologi Radiasi Panas Pada Pengolahan Sawit Terpadu, Jurnal Industri Hasil Perkebunan, Vol 12. No 2, Makasar

2. Anderson, CR., LM Condron, TJ Clough, M Fiers, AStewart, RAHill, RR Sherlock. 2011. Biochar induced soi Imicrobial community change: Implications for biogeochemical cycling of carbon, nitrogen and phosphorus. Pedobiologia-International Journal of Soil Biology. 54, 309-320.

3. Budijanto, S., Hasbullah, R., Prabawati, S., Setiyajit, Sukarno, dan Zuraida, I., 2008. Identifikasi dan Uji Keamanan Asap Cair Tempurung Kelapa Untuk Produk Pangan. Jurnal Pascapanen, Vol. 5. No. 1. Hal. 32-40.

4. Demirbas, A. 2005. Pyrolysis of ground beech wood in irregular heating rate conditions. Journal of Analytical Applied and Pyrolysis. 73:39-43.

5. Detik, 2017. Dirjen Perkebunan: Sawit Sumbang Sumber Devisa Rp. 239 Triilun, http://www.rmol.co/ $\mathrm{read} / 2017 / 08 / 29 / 304956 / D i r j e n-$ Perkebunan:-Sawit-SumbangSumber-Devisa-Rp-239-Triliun-, 29 Agustus 2017

6. Di Blasi, C., 2008, "Modeling Chemical and Physical Processes of Wood and Biomass Pyrolisis", Progress in Energy and Combustion Science 34, 47-99

7. Dzaki Maruf. 2017. Pasang Surut Fitnah Uni Eropa dan Prospek Minyak Sawit Indonesia. https://www.kompasiana. com/dzakirmaruf/pasang-surutfitnah-uni-eropa-dan-Kompas, Kompas, 8 juni 2017
8. Gani, A., 2007, Konversi Sampah Organik Pasar Menjadi Komarasca (Kompos-Arang Aktif-Asap Cair) dan Aplikasinya pada Tanaman Daun Dewa. Thesis. Sekolah Pascasarjana, Institut Pertanian Bogor. Bogor

9. Girrard, J.P., 1992, Technology of Meat and Meat Products, Ellis Horwood, New York

10. Guillen, M.D., M.J. Manzanosand L. Zabala. 1995. Study of commercial liquid smoke flavoring by means of Gas Chromatography-Mass Spectrometry and Fourier transporm Infra red Spectroscopy. J Agric Food Chem, 43:463-468.

11. Guillen, M.D., P. Sopelana and M.A. Partearroyo. 2000. Polycyclic aromati chydrocarbons in liquid smoke flavorings obtained from different types of wood, effect of storage in polyethylene flasks on their concentrations. J Agric Food Chem, 48: 5083-6087

12. Guillen, M.D., M.J. Manzanos and M.L. Ibargoitia. 2001. Carbohydrate and nitrogenated compounds in liquid smoke flavorings. J Agric Food Chem, 49:2395-2403.

13. Jayanudin dan Endang Suhendi, 2012, Identifikasi Koponen Kimia Asap Cair Tempurung Kelapa dari WilayahAnyer Banten, Jurnal Agroekoteknologi, Vol 4, No.1

14. Karseno, P. Darmadji dan K. Rahayu. 2002. Daya hambat asap cair kayu karet terhadap bakteri pengkontaminan lateks dan ribbed smoke sheet. Agritech, 21(1):10-15

15. Liu H., S Kong, Y Liu, H Zeng. 2012. Pollution control technologies of dioxins in municipal solid waste incinerator. Procedia Environmental Sciences, 16, 661-668

16. Luditama, dan Candra. 2006. Isolasi dan Pemurnian Asap Cair Berbahan DasarTempurung dan Sabut Kelapa Secara Pirolisis dan Distilasi. Skripsi. Fakultas Teknologi Pertanian, Institut Pertanian Bogor. 
17. Mangoensoekarjo S dan H. Semangun. 2005. Manajemen Agribisnis Kelapa Sawit. Gadjah Mada University Press. Yogyakarta.

18. Noor, I.M. 2015. Sudah Saatnya Memodernkan Pabrik Kelapa Sawit Indonesia Untuk Lebih Kuat dan Mandiri dengan FASTLURR TECHNOLOGY, PT. Noor Amalindo, Jakarta.

19. Plaza, C., B. Giannetta, JM. Fernadez, EG. Lopez-de-Sa, A. Polo, G. Gasco, A. Mendez, C. Zaccone. 2016. Response of different soil organic matter pools to biochar and organic fertilizers. Agriculture, Ecosystems and Environment, 225. 150-159.

20. Putnam, K.P., D.W. Bombick, J.T. Avalosand D.J. Doolittle. 1999. Comparison of the cytotoxic and mutagenic potential of liquid smoke food flavourings, cigarette smoke condensate and wood smoke condensate. Food Chem Toxicol, 37:1113-1118.

21. Setyamidjaja, D., 2006. Kelapa Sawit Teknik Budidaya, Panen dan Pengolahan. Kanisius, Yogyakarta. 